\title{
ENSAIO DE ESTUDIOSOS DA CULTURA, DIÁLOGO DE DIFERENTE TEMPO E PONTO DE VISTA
}

\author{
TESTING OF CULTURE STUDIOS: THE DISASSEMBLY OF CULTURE IN BRAZIL
}

\section{Pedro Paulo Almeida Martins ${ }^{1}$}

RESUMO: O artigo visa viabilizar um diálogo, entre os autores, seus diferentes pontos de vista epistêmicos, situando no decorrer do conceito de cultura, estabelecido, e o que é a cultura, no ensaio e conversação para cada autor tem um significado. Neste processo de cultura, o homem, quando ocupa espaço da sua existência, pode-se destacar que tem a racionalidade para elaborar suas condutas e criam suas identidades, usa a razão, embora que diferencia do ser irracional pela fala e comportamento sociocultural, neste plano terreno, passageiro para produzir e reproduzir cultura. Assim define, em consonância, ainda quando o ser humano está incomodando alguns, referente as boas atitudes, seria um bom sinal, uma inclinação no caminho certo, a moral do indivíduo define atitudes e comportamentos com os outros, se o ser sabe da sua identidade, sua existência como pessoa humana, estará produzindo e reproduzindo cultura consciente e inconscientemente na interação social, diante da acepção do juízo de valor, seja em afirmações do diante e perante as culturas que seria a medida de respeitar os costumes, valores e rituais do outro ser humano. Na condição humano, o ser é parte do todo, se coloca o homem e um animal irracional, o animal tem seu instinto e o ser humano tem na sua natureza humana, um mundo não natural, a possibilidade de transformar à vida, desenvolver cultura e sobreviver, logo criam infinitas possibilidades possíveis por meio da cultura. Nos estudos da antropologia, que explica o estudo do homem, a resposta é desde o homem constrói e produz seu processo de sobrevivência, nessa simbiose, o contato e habilidades de interpretação dos signos e simbologia, criam possibilidades de pluralidade cultural.

Palavras-chaves: Pontos de vistas epistêmicos sobre cultura. Cultura. Interação social.

ABSTRACT: The article aims to enable a dialogue between the authors, their different epistemic points of view, placing in the course of the established concept of culture, and what is culture, in the essay and conversation, for each author it has a meaning. In this cultural process, man, when occupying space in his existence, it can be highlighted that he has the rationality to elaborate his behaviors and create their identities, he uses reason, although he differentiates from being irrational through speech and sociocultural behavior, on this level land, which is temporary to produce and reproduce culture. Thus defines, in

\footnotetext{
I Acadêmico do curso Direito na Faculdade Católica de Rondônia- FCR e graduando em Ciências Sociais na Universidade Federal de Rondônia - UNIR, Porto Velho, Brasil; Pedro Paulo Almeida Martins, Bibliotecário, tecnólogo em Gestão pública, 4 titulações de pós-graduado: Especialista em Gestão Pública, metodologia do ensino superior em Língua Portuguesa, Biblioteconomia e MBA em Governança e Gestão Administrativa, , E-mail: pedropaulogestorpublico@gmail,com, currículo Lattes: http://lattes.cnpq.br/3951670487194507 Orcid: https://orcid.org/oooo-ooo2-349o-8784
} 
line, even when the human being is bothering some, referring to good attitudes, it would be a good sign, an inclination that is on the right path, the individual's morals define attitudes and behaviors with others, if the being knows about the their identity, their existence as a human person, will be producing and reproducing culture consciously and unconsciously in social interaction, given the meaning of value judgment, whether in statements from before and before cultures, which would be the measure of respecting customs, values and rituals of the other human being. In the human condition, being is part of the whole, man and an irrational animal are placed, the animal has its instinct and the human being has in its human nature, an unnatural world, the possibility of transforming life, developing culture and survive, then create infinite possible possibilities through culture. In the studies of anthropology, which explains the study of man, the answer is from the moment that man starts to build and produce his survival process, in this symbiosis, the contact and interpretation skills of signs and symbology create possibilities for plurality cultural.

Keywords: Epistemic views on culture. Culture. Social interaction.

\section{INTRODUÇÃO}

Em primeiro lugar, para preambular, sobre o conceito de cultura na área do conhecimento da antropologia, conforme consta no dicionário Aurélio Online, geralmente, a cultura pode ter significado desde: ato, arte, modo de cultivar, 2. Lavoura, 3. Conjunto das operações necessárias para que à terra produza, 4. Vegetal cultivado, 5. Meio de conservar, aumentar e utilizar certos produtos naturais, 6. Aplicação do espírito a (determinado estudo ou trabalho intelectual),7. Instrução, saber, estudo,8. A puro; perfeição; cuidado.

\footnotetext{
Diante do Site Brasil Escola $(202 \mathrm{I})^{2}$ o sentido de cultura é amplo. O que nos interessa aqui é saber que a cultura corresponde a um conjunto de hábitos, crenças e conhecimentos de um povo ou um determinado grupo artístico (literário, dramatúrgico, musical, derivado das artes plásticas etc.) que cultiva, de algum modo, um padrão estético semelhante. Focando no termo cultura observado pelo viés da Sociologia e da Antropologia, podemos dizer que "é por meio da cultura que buscamos soluções para nossos problemas cotidianos, interpretamos a realidade e produzimos novas formas de interação social”. Essa teoria, obviamente, leva em consideração as noções não somente geográficas, mas também étnicas para separar os diferentes povos, o que permite a percepção, nos dias de hoje, de que o darwinismo social era uma ótica eurocêntrica e racista apoiada em um método científico. Outro grande nome a integrar o espectro do darwinismo ou evolucionismo social foi o também britânico, considerado o primeiro antropólogo da Inglaterra, Edward Burnett Tylor. O "pai" da Antropologia britânica revolucionou o conceito de cultura para aplicá-lo em amplo aspecto em sociedades, porém ele estava ligado a uma visão
}

${ }^{2}$ Disponívelem<https://brasilescola.uol.com.br/cultura\#: :text=O\%2osentido\%2ode\%20cultura\%20\% 3 \% $\%$ A9, deriva do\%2odas\%20artes\%2opl\%C3\%Arsticas\%2oetc.) >Acesso em: 20 de Maio de 202I. 
que mais tarde seria descartada do estudo social científico, por estabelecer hierarquias sociais a partir da produção cultural.

Já consta, na obra de referência, do autor:

O dicionário de filosofia ${ }^{3}$, tornou-se corrente na cultura contemporânea, não só na descrição do trabalho operário em certas fases da sociedade capitalista, mas também a propósito da relação entre o homem e as coisas na era tecnológica, já que parece que o predomínio da técnica "aliena o homem em si mesmo" no sentido de que tende a fazer dele a engrenagem de uma máquina. (Abbagnano, 202I)

Segundo dados do Jornal eletrônico, (Carta Capital,202I), não se pode desconsiderar o que vem acontecendo, em nosso país, tem uma situação temerária e complexa, a esclarecer que, diante das informações dos meios de comunicação de massa, em 2020, o governo Bolsonaro, cortaram $80 \%$ da verba voltado para investimento na área da cultura, infelizmente essa contenção de gasto de $78 \%$ na dotação orçamentária direcionado à cultura para o ano de 202I foi restritiva. Vale destacar que esse o desmonte está sendo efetuado, do Ministério da Cultura foi extirpado no primeiro ano de governo, logo criou a Secretaria Especial da Cultura. Segundo consta a lei Rouanet, que fomenta, manifestação cultural através da 7 arte, cinema e demais criações culturais na amplitude da cultura do Brasil, qual papel da cultura num país cosmopolita e multicultural como o Brasil, o fazer de conta, o desrespeito é algo que, entretanto, reproduz são pessoas que não gostam da cultura, o estado de arte. Vale um pouco conhecer, o conceito, explicaremos a definição de cultura, qual sentido! tem uma definição bem ampla, geralmente é sistema de signos de uma cultura, ou seja, a maneira e costumes, manifestados por um povo através de princípios e valores socioculturais, ou seja, o carnaval e a festa juninas são formas que existem muitos anos na nação. Acima de tudo, entrando nos pressupostos dos autores da área, rompe com funcionalismo de Malinowski, estrutura maiores de Lévi-Strauss, Se eu quero compreender a cultura, vou para ação do indivíduo, sai do campo macro para o campo micro, olhar para o pódio indivíduo, quais significados do ser humano na condição humana têm nas formas de ações, se espelha em Max, sociologia compreensiva..., isso é a ação social ele atribui significado, a existência de outras pessoas na realidade, ir para igreja, qual sentido vai para igreja para aprender mais sobre religião... atribui sentido significado a

\footnotetext{
${ }^{3}$ ABBAGNANO, Nicola. Dicionário de filosofia. Tradução de Alfredo Bosi e Ivone Castilho Benedetti. São Paulo: Martins Fontes, 2007.
} 
ação, uma sinergia em viver numa sociabilidade. Porquanto, o autor contemporâneo do Século 20 e 2I, Geertz, tem uma abordagem da antropologia interpretativa, vai de encontro e explica que, para compreender o fenômeno cultural, lança no livro s interpretação. Além disso, Geertz na obra, com conceito: "o todo mais complexo" explica na antropologia que o autor complica a explicação do termo cultura, termo citado por na sua abordagem, mais que clarifica sobre o tema, no próprio desenvolver de sua teoria. $\mathrm{O}$ autor no discorrer relata sobre a maneira de agir e globalmente por uma por povo com fatores tradicionais que um ser social alcança, abstração das atitudes, ou seja, da forma de se portar. Outrossim, o comportamento aprendido, o autor coaduna, (GEERTZ,I994,p.I4) ” o conceito de cultura que defendo, e cuja utilidade os ensaios abaixo tentam demonstrar, é essencialmente semiótico. Acreditando, como Max 'weber', que o homem é um animal amarrado a teias de significados que ele mesmo teceu, assumo a cultura como sendo essas teias e a sua análise; portanto, não como uma ciência experimental em busca de leis, mas como uma ciência interpretativa, à procura do significado. É justamente uma explicação que procuro, ao construir expressões sociais enigmáticas na sua superfície. Todavia, essa afirmativa, uma doutrina numa cláusula, requer por si mesma uma explicação" Ainda por cima, o foco de Geertz é que cada indivíduo atribui verso significados diversos, cada um significado, um simbolismo, o conjunto em sinergia de todos quando inter-relacionam quando fazem socialização primária, uma forma de mobilidade social no futuro... Cada ação social sempre orientado em outras pessoas... Como ser atribui sentido e haver com os seres, nesse processo de humanização, entende-se, uma pessoa que faz parte de um processo no todo, deve respeito e ser respeitada, como no fato social, regra de boa convivência deve ser respeitada, por exemplo, nesse processo de humanização, em convívio humano, um ser, que está em constante absorção de conhecimento, a todo o momento. "Como sustenta Aristóteles, no tocante a ética, emoções e sentimentos são benéficos para moralidade (TORRES, 2014, p.IIo)”, em reflexão, embora infelizmente, se um colega, de maneira hipotética, realiza isso como estudante, com o outro, naquilo que consiste a moral. Ao analisar até aqui, vale definir ação social, visa compreender essa cadeia de significado nas ações, o simbolismo, os signos da cultura, em determinado contexto da situação na sociedade, o funcionamento da cultura por completo, seria uma indução de conexões, a etnografia é algo importante e dar forma aos significados do simbolismo, como descrição 
densa de significados variados para um, momento de aprendizagem única, por exemplo, ensino remoto, atribuir significado, uns darão importância ao ensino, estudaram como estivessem em ensino presencial, pois o objetivo a alcançar é maior que tudo..., assim vale ressaltar que, em nada alterará o ensino aprendizagem, salientado diante do processo de ensino aprendizagem, que seria aluno-professor, como diz Paulo Freire na sua obra a pedagogia do oprimido, e Libâneo coaduna com a mesma forma de pensar que Geertz, no caso do exemplo que estou mencionando, sinaliza na obra Didática, referenciado no capítulo 8, as formas de organização de aula, dar valor que é um Monet para aprender, uma possibilidade de aprender, do presencial para o retomo agora atribuir o mesmo significado. Aí verifica o momento em significado que as pessoas atribuem no mundo alteram o significado da cultura. O foco é como, o indivíduo na sua condição humana, dará significado nas suas ações.

Na obra de Clifford Geertz, a atenção às formas e à força da significação cultural se aproxima de uma estetização da vida cultural e dos procedimentos usados para interpretá-la, embora seja importante observar o sentido deveras específico que Geertz dá ao termo "estético". Ele afirma ser necessário, ao considerar a atividade artística, evitar os dois tipos de falsificação etnocêntrica: o que implica a realização, em sociedades primitivas, da visão schilleriana de uma existência totalmente estética e o que supõe que a posição da arte nessas sociedades é tão altamente especializada quanto na nossa. Contra a primeira falsificação, é necessário admitir os graus relativos de especialização da atividade artística e estética no âmbito de diferentes culturas, mesmo que, contra a segunda, se mantenha a sensibilidade para com as maneiras como a qualidade ou valor particular do estético em toda sociedade tem que ver com o seu lugar num panorama cultural geral. (CONNOR Apud GEERTZ, 1994, p.238)

Podemos citar Ayala (1995), explica um pouco de cultura popular no Brasil, toda característica que o ser humano produz símbolos e signos, simbolismos no coletivo diante da tradição, mas na ordem de coletividade como hábitos e valores, e se manifesta na forma falada, a cultura popular é migratória de popular para erudita, já definia Bourdieu que cultura são específicas de classes sociais, acessar obras acadêmicas, determina o capital cultural elevado, principalmente o acesso à obra de arte, o teatro é cultura erudita, diferente do "funk" das favelas, o capitalismo produziu cultura de massa seria massificação cultural, devido à produção com algo voltado como mercadoria cultural para atingir o lucro, o cinema atinge a vários públicos, mas com cunho mercadológico para venda e geração de riqueza. 
Tal fato representa um tipo de comportamento padronizado por um sistema cultural. Esta atitude varia em outras culturas. Entre algu mas tribos das planícies norte-americanas, o homossexual era visto como um ser dotado de propriedades mágicas, capaz de servir de mediador entre o mundo social e o sobrenatural, e portanto respeitado. Um outro exemplo de atitude diferente de comportamento desviante encontramos entre alguns povos da Antiguidade, onde a prostituição não constituía um fato anômalo: jovens da Lícia praticavam relações sexuais em troca de moedas de ouro, a fim de acumular um dote para o casamento. (LARAIA, p.68, 2009)

O modo de observar o mundo, as apreciações de ordem moral e valorativa, os diferentes comportamentos sociais e mesmo as posturas corporais são assim produtos de uma herança cultural, ou seja, o resultado da operação de uma determinada cultura. Graças ao que foi dito acima, podemos entender que indivíduos de culturas diferentes podem ser fácil mente identificados por uma série de características, tais como o modo de agir, vestir, caminhar, comer, sem mencionar a evidência das diferenças linguísticas, o fato de mais imediata observação empírica.

\footnotetext{
Mas, qualquer que seja a sociedade, não existe a possibilidade de um indivíduo dominar todos os aspectos de sua cultura. Isto porque, como afirmou Marion Levy Jr., "nenhum sistema de socialização é idealmente perfeito, em nenhuma sociedade são todos os indivíduos igualmente bem socializados, e ninguém é perfeitamente socializado. Um indivíduo não pode ser igualmente familiarizado com todos os aspectos de sua sociedade; pelo contrário, ele pode permanecer completamente ignorante a respeito de alguns aspectos". Exemplificando: Einstein era um gênio na física, um medíocre violinista e, provavelmente, seria um completo desastre como pintor. (LARAIA, p.82, 2009)
}

Para Laraia (2009), com conceito de Cultura um conceito antropológico, assim escreve no seu compêndio de maneira acessível, construção de conceito de Cultura como funciona a cultura, sua influência na sociedade de maneira individual, é criada na sociedade. A natureza é a mesma, o que diferencia um ser do (oito) são hábitos, um homem diferencia dos outros animais por ter cultural. Connor (1994) coaduna que cultura seria a manifestação do ser humano frente o saber,os costumes e conjuntos de manifestações que o indivíduo tem nas interações sociais. Porém, enxerga como problema na sociedade que desintegra e dissolve entre as culturas ocidentais separou conforme a forma de manifestação, do estético a susceptível inclusão do não-ocidental, com produção cultural de mitos, alienação cultural na sociedade. Demonstra que cultura, já Rousseau que, a cultura é baseada no aprendizado só temos cultura quando absorvemos, interagindo e geramos cultura. Ou seja, certamente existe pela forma de comunicação formal e informal, 
seriam símbolos de fala e escrita, simbolismo para decodificar as informações que seriam maneira de pressupostos culturais, no tocante ao armazenamento informação ao gerar cultura nesse ciclo de aprendizado do homem, ou seja, ao assimilar, gerar e transmitir conhecimento, podemos dizer que seja cultura, fatores culturais, por exemplo, o efeito placebo, comer manga com sal, comer e tomar banho...

(CONNOR, 1994, p.244) (1869), de Matthew Arnold, e Primitive Culture (1871), de E. B. Tylor. Para Arnold, cultura é definida como a "busca desinteressada da perfei ção..., a simples tentativa de ver as coisas tal como são, a fim de aceitar o melhor e fazê-lo prevalecer"; e, mais uma vez, "permitir a si mesmo, seja mediante a leitura, a observação ou o pensamento, chegar o mais próximo possível da firme lei inteligível das coisas e, desse modo, formar a base de uma ação menos confusa e de uma perfeição mais completa do que temos no presente". A grande inovação de Primitive Culture, de El B. Tylor, é, por outro lado, a sua abrangência, como o indica a sua afir mação inicial de que "Cultura ou Civilização, tomadas em seu sentido etnográfico amplo, são o todo complexo que inclui o conhecimento, as crenças, hábitos artísticos, costumes legais e quaisquer outras capacida des e hábitos adquiridos pelo homem como membro da sociedade. Refu tando a austera distinção de Arnold entre o "maquinário" ou meios da cultura e os seus fins desinteressados, transcendentes, Tylor supõe a ampla sinonímia entre as palavras "cultura" e "civilização".

Para Laplantine (1988) para Tylor não existem culturas, mas sim existem culturas,

pois a cultura se representa de maneira diferente porque a sociedade está em diferente estágio de transformação. No caso Morgan, influencia o pensamento moderno e tem suas contribuições no próprio tempo dos estudos. A cultura se representa diferentemente, assim define quando faz uma relação entre a sociedade humana na selvageria, que transpassa pela barbárie e até ir de encontro a civilização, pois de fato pode-se destacar que a sociedade está em constante estágio evolutivo, pelo processo de sociabilização que acontece por meio das interações sociais, pois cultura seria um conjunto complexo de crença, valores e tradição, no caso, nesse processo, a criança vê faz tudo, a criança vê, a criança faz e aprende, as regras do convívio social são colocadas no processo de socialização, sempre estamos em aquisição de cultura, nessa exterioridade, quando nasce a cultura já existe, no contato social de tradição externa, numa interpretação, um dia esta criança será um adulto com hábitos, costumes e predileções. Mas, apesar das diferenças formas, há um nível em que Arnold e Tylor estão articulando uma experiência compartilhada. George Stocking detalhou os modos pelos quais o relato da cultura de Tylor, embora evidentemente concebido como uma espécie de réplica ao de Arnold, na realidade, depende de um privilégio teleológico similar atribuído ao ideal da civilização avançada e de uma tendência a avaliar as culturas 

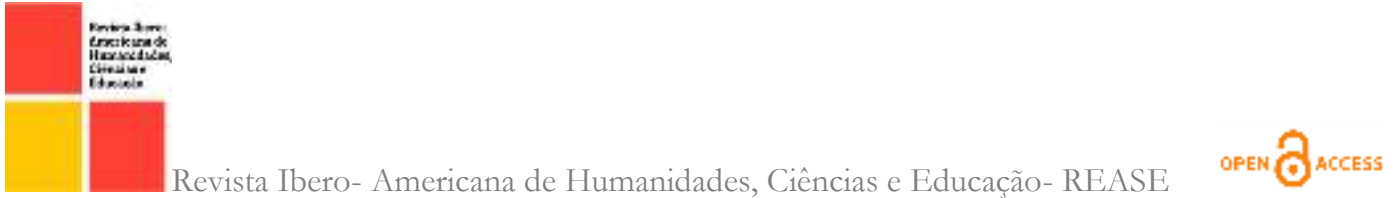

selvagens ou bárbaras em termos de sua distância, ou proximidade desse ponto mais alto do desenvolvimento cultural. Para os dois, bem como para muitos outros críticos do século XIX, a noção de cultura também encarna um ideal de desenvolvimento na direção da integralidade, um ideal afirmado diante da crescente consciência da cisão ou fragmentação cultural. O ideal arnoldiano de "perfeição harmoniosa da nossa humanidade" se une, por conseguinte, à apreensão metodológica de Tylor da unidade do processo de desenvolvimento cultural das culturas primitivas para as avançadas. Como disse James Clifford de Arnold e de Tylor, bem como do seu legado conjunto à antropologia, "uma forte estrutura de sentimento continua a constatar a cultura, onde quer que ela se faça presente, como um corpo coerente que vive e morre. A cultura é antes duradoura, tradicional e estrutural do que contingente, sincrética, histórica. A cultura é um processo de ordenamento, não de fragmentação"Essa associação entre o estético e o antropológico séria consolidada no primitivismo maduro de boa parte da teoria modernista, A cultura é etnocêntrica para Laraia (2009), tem visões diversas, desencontradas, a partir do contexto histórico do outro na sociedade, toda cultura é algo que eu criada e se convergem. Muitos no conhecem as culturas opostas, deve respeitar, por exemplo, no Big Brother Brasil- BBB, um estudo de cultura, de choque de realidade diferenciada, diversas pessoas com hábitos e formas de vida diferenciadas, cada um tem sua forma de vida e criação, seus valores com princípios e virtudes. Perante as ideias de Simon (1995), no livro: Culture in transit, em que, em síntese, discorre sobre a cultura, a identidade do migrante em transição, ou seja, o imigrante leva sua cultura de maneira que pode influenciar outras culturas pelo universo. Assim vale destacar a diversidade de culturas vinda para o Brasil, por exemplo, em casos de apoio, refugiados que apoiaram no Brasil, uma oportunidade, nos 2000 à 2021, pode-se detalhar alguns países (Síria, Líbano, Irã, Venezuela, Haiti), em crise humanitária, transitam e migrar carregando suas culturas, podendo interferir nas demais culturas, principalmente no tocante a simbiose, a interação social, todos estão passíveis de aprendizado. $\mathrm{Na}$ obra de Durkheim as formas elementares religiosas, investiga através da consciência coletiva, resultado por estudos diante da problemática, uma religião primitiva, o totemismo das tribos australianas, diferença entre o sagrado e profano algo partilhados pelas religiões,... cultura (sistema) de representação religiosa, o crente ligado ao sagrado baseado no culto, o sobrenatural, função social não é definida, a religião não é definida pela 
crença, mas o que liga é a união de todos no bem comum, quando estão na igreja... Totemismo Deus, uma forma anônima, sobrenatural força do totem $\mathrm{m}$ um talismã, uma força de causalidade, descreve culto que ligam crentes ao sagrado, culto negativo seria o profano, diante da organização social, consciência coletiva no fenômeno social, sustentando a coerção social, proibições de vestimentas e abstenção de coisas sagradas. Conforme a obra de Cascudo (1983), ao pensamento e disseminação do saber, uso costumes e raízes, saberes, o folclorismo era visto como patrimônio cultural que enriquece no Brasil, o movimento cultural em diversas regiões pelo Brasil. Pesquisa sobre cultura e folclore, a cultura seria mistura de lendas, com base no folclore no Brasil, o autor escreveu sobre nossa cultura que é diversa, a produção se baseia na interação que vai do aperto de mão e etc., na socialização primária ou secundária, seja na escola ou na sociedade em geral.

CONNOR APUD TYLOR ARNOLD (p.236, 1996) nas respectivas formulações de Tylor e Arnold envolvem por sua vez duas atitudes distintas com respeito à questão do valor, se bem que, em ambos os casos, se deva considerar "cultura", em certo sentido, sinônimo de "valor". No sentido antropológico do termo, a atividade cultural representa o jogo do valor, todos os sistemas múltiplos e sobrepostos de equivalência e troca que servem de mediação às diferentes esferas da atividade económica e simbólica.

Já para:

\begin{abstract}
Alguns de seus estudos publicados em revistas e jornais, entre 1942 e 1962 , foram reunidos em duas obras. A leitura desse conjunto de ensaios permite verificar mudanças nas concepções do Autor, ao longo do tempo, a respeito da especificidade dos estudos de folclore e do papel das ciências sociais nessa área. (FLORESTAN FERNANDES APUD AYALA 1995, p.34)
\end{abstract}

Uma das preocupações centrais de Florestan Fernandes, como ele próprio salienta, é tornar efetiva a análise do folclore como realidade social. Critica os folcloristas por se limitarem a repetir essa noção sem que a observação, descrição e interpretação por eles realizadas permitam, de fato, apreender o social nas manifestações populares em questão. Essa falta de coerência entre o propósito anunciado e os procedi mentos adotados está imbricada com o que Amadeu Ama

Assim, citado por Florestan Fernandes, denominou " um pernicioso diletantismo"

CULTURA, de cultum, supino de colere, trabalho da terra, conjunto de operações próprias para obter do solo os vegetais cultivados. Cultura de batatas. Cultura de milho. Sinônimo de agricultura, lavoura, trabalho rural, cultura agri. Fundar cultura era plantar uma determinada espécie ou aproveitar o ter reno com um plantio apropriado. Figuradamente, 
analógica mente, cultura das letras, das ciências, das belas-artes. Sempre numa aplicação parcial, específica, localizada. Era ainda o cri tério francês que o Larousse servia de porta-voz: culture, étude, application de l'esprit à une chose. La culture des beaux-arts, des sciences. Développement que l'on donne, par des soins as sidus, à des facultés naturelles. Entende-se que a cultura era um exercício da inteligência aplicado a um esforço para finalidade determinada e única. Nunca o geral, o conjunto, a totalidade. É um músculo, um órgão, um nervo. Jamais o orga nismo inteiro. Um rio, uma árvore, uma montanha. paisagem completa. (CASCUDO, 1983, p.39)

Para fins primários de impressão poder-se-ia dizer que a cultura é o conjunto de técnicas de produção, reprodução, doutrinas e atos, transmissível pela convivência e ensino, de geração em geração. Compreende-se que exista processo lento ou rápido de modificações, supressões, mutilações parciais no terreno material ou espiritual do coletivo sem que determine uma transformação anuladora das permanências características.

No Brasil não tivemos o vocábulo na acepção presente vindo de nenhum país latino. Recebemo-lo dos norte-americanos, etnólogos, antropologistas e especialmente pedagogistas, forma inicial e poderosa da influência intelectual americana na América do Sul. Os norte-americanos tiveram cultura do alemão Kultur, que orgulha a todo germânico pronunciá-la, batendo os calcanhares. Civilização, civitas-civitatis, ligava-se totalmente à ideia de Estado, conjunto de cidadãos reunidos em sociedade, realizando os fins da vida organizada nesse âmbito (M. Block). (CASCUDO, 1983, p39-40)

Nos estudos de Stuart Hall, com base na literatura proposta, analisamos o conceito de globalização, bem como o surgimento do fenômeno do multiculturalismo como conceito e experiência relacionados ao mundo global, as diversas culturas frente ao pluralismo e diversidade cultural. Em seguida, discute-se a questão da diversidade cultural e das relações interculturais surgidas a partir da articulação entre multiculturalismo e globalização. (HALL, 2006) O multiculturalismo é algo intrínseco sendo precedido da globalização, processo rápido, integral e real que possui suas relações de integração entre as nações que produzem informações constantemente a cada dia, ou seja, esse comércio internacional impõe regras que torna a ser forçado para cumprir o sistema. Esse multiculturalismo tem representação da mistura relacionada entre as culturas e práticas que leva a composição da cultural social que acaba sendo sua espinha dorsal. Do mesmo modo, o autor continua sua análise levantando três questões de fundamental importância para a compreensão do processo globalizatório. Com base nestes instrumentos as identidades de seus locais estão se desestruturando devido o aumento exponencial da adaptação dessas misturas de raças culturais que vão se mesclando, essa troca cultural que, 
ao mesmo tempo em que contribui recebe influência. Nesta circunstância, entende-se que esse processo vem desfragmentando, deixando fraca a cultura existente, por força da ação de impor novos formatos de costumes e tradições no núcleo das culturas, contudo essa cultura estabelecida se molda, muitas se mescla ou até pode apagar a identidade com a soma das novas tendências, levando assim ao colapso e enfraquecimento.

As classes sociais mais altas acabam por influenciar as mais baixas, inclusive em
razão do monopólio dos meios de comunicação em massa, que criam estereótipos,
modelos, comportamentos etc. Portanto, não se pode dizer que o crime é uma
forma de comportamento inadaptado das classes menos favorecidas. Não é
exclusividade delas, porque assistimos a uma série de crimes de colarinho branco
(sonegações, fraudes etc.), que são delitos praticados por pessoas de elevada
estatura social e respeitadas no ambiente profissional (empresários, políticos,
industriais etc.). Nem todas as associações diferenciais têm a mesma força;
variam na frequência, na duração, interesses e na intensidade. (FILHO, p.59,
20I8)

Daí porque a teoria conduz à ideia de que a cultura mais ampla não é homogênea, levando a conceitos contraditórios do mesmo comportamento, porque se nega que o comportamento do delinquente possa ser explicado por necessidades e valores gerais.

${ }^{4} \mathrm{~A}$ identidade, nessa concepção sociológica, preenche o espaço entre o "interior"
"exterior"- entre o mundo pessoal e o mundo público. O fato de que projetamos a
"nós pró prios nessas identidades culturais, ao mesmo tempo que internalizamos
seus significados e valores, tornando-os "parte de nós", contri bui para alinhar
nossos sentimentos subjetivos com os lugares objetivos que ocupamos no mundo
social e cultural. A identidade, então, costura (ou, para usar uma metáfora
médica. "sutura") o sujeito à estrutura. Estabiliza tanto os sujeitos quanto os
mundos culturais que eles habitam, tornando ambos recíproca mente mais
unificados e predizíveis. (HALL, p.I2, 2oII) 1010

Segundo Anitua (2008), nos estudos da teoria das associações diferencias, criminalidade de colarinho branco, teve interessante enfoque no século XXI Edwin Sutherland, estudioso que se juntou a aclamada Escola de Chicago, o objeto de estudo era o infrator, conhecido por Sutherland, como crime de colarinho branco, em busca de explicar os efeitos organicamente, assim definido por Durkheim e o comportamento do indivíduo, no aspecto psicológico Vygotsky coaduna, com a tese, no processo de aprendizagem, atrelado ao psicológico, desconstruindo o fator que criticavam o referente crime atrelado aos fatores socioeconômicos, ou seja, a pobreza, assim Sutherland, indo contra o pensar daquela época da idade média, com oposição de ideias de alguns pensadores da época,

\footnotetext{
${ }^{4}$ HALL, Stuart. A identidade cultural na pós-modernidade.IIed. Belo Horizonte: DP\&A editora, 2003.99p.
} 
construindo nova ideias que teciam críticas nesta dualidade, estudiosos do estado que dar apoio, assim Sutherland usava a expressão desarranjo sociável. Considerava o autor (Vygotsky, 1992,p.23) que conhecia que na psicologia da educação no Brasil: "As proposições de Vygotsky acerca de processo de forma de conceitos nos remetem à discussão das relações entre o pensamento à linguagem, mediação cultural no processo de construção de significado por parte do indivíduo, ao processo de internalização e ao papel da interação social”. Define Ralph Linton (1893-1953): “Como termo geral, cultura significa a herança social e total da Humanidade; como termo específico, uma cultura significa determinada variante da herança social. Assim, cultura, na totalidade, compõe se de grande número de culturas, cada uma das quais é característica de um certo grupo de indivíduos” (O Homem, uma Introdução à Antropologia. São Paulo, 1943). "Pereira Apud Bauman, 2012, p.3, sinaliza nos estudos: Por fim, Bauman trata cultura e sociologia avaliando extensamente as formas como esta estudou o campo cultural ao longo de sua jornada científica e chega ao entendimento de que a cultura é singularmente humana, pois apenas os seres humanos podem reivindicar um significado mais profundo"

\section{CONSIDERAÇÕES FINAIS}

Afinal, o artigo fez um ensaio entre diversos autores, com cada ponto epistêmicos, ponto de vista, referente à cultura na sociedade, pode-se afirmar que trazendo toda discussão para o campo da política, podemos elucidar algumas indagações referente corrupção em relação a cultura, levando para uma análise da capacidade de destreza do ser humano, frente a sua existência, como parte de um todo, para característica na capacidade espelhado pelos outros de maneira tanto positiva e assertiva ou desvirtuada da moral, dos princípios e virtudes. Essas ações desordenadas não assertivas são prontificadas diante da ação-reação, usando como exemplo, observando os fatores socioculturais inseridos e aprendidos da corrupção, por exemplo, seja do criminoso frente ato de corrupção ou demais vantagens ilícita, muitos falam que é a cultura do brasileiro, no jargão popular, o conhecimento popular, o famoso jeitinho brasileiro de que aprende a roubar e ter conduta desvirtuada, alguns políticos em Brasília, logo, não pode fazer diferença desde o que furta um carro, ou rouba moto até o bandido que rouba dinheiro dos cofres públicos em esquemas, frauda um sistema financeiro, faz suborno, esquema de pirâmide, extorsão, 
falsidade ideológica, pirataria moderna, assim como os últimos crimes: lavagem de dinheiro, corrupção ativa e corrupção ativa, sendo crime mais constante que observamos por meio dos meios de comunicação de massa no Brasil, uma cultura que diariamente escorrem escândalos diversos, seja pela: televisão, rádio e a "internet", noticiários de corrupção envolvendo pessoas no Planalto, Congresso e Câmara do Brasil, até no aspecto religioso, líderes religiosos usam da influência para cometer crimes de conduta sofisticada de organização criminosa e lavagem de dinheiro $^{1}$ e observa-se que o crime se aprende diante das atitudes dos outros, tem um fator, cultura, será que os aqui descentes das caravelas de Cabral deu uma descendência ?, talvez não achamos explicação, mas o sistema está aí, uma roda, engrenagem sistemática, no entanto, corrompe que entra neste jogo, desde a governabilidade (forma e ações para conduzirem a política e ter uma possível harmonia) quer dizer, algo que existe depende das ações e atitudes do indivíduo, se cometerá crime previsto em lei ou não vai cometer o crime, por exemplo, no processo de governança, quando tem recursos, fundos para manutenção dos direitos sociais Art. 6 CRFB, acaba sendo um problema, onde tem dinheiro, empresas, poder nas ações para um Estado manter seja por meio do, os projetos prioritários, garantidos com políticas públicas efetivas, vislumbra-se, aí o jogo do toma-la-da-cá, na linguagem popular, o conflito de interesses, algo que vai trazer benefício, infelizmente, existe uma corrupção que é sistêmica, fatores culturais relevantes nos aspectos, que permeia a sociedade guiada pela necropolítica bolsonarista, além de frutos de corrupções, de gerenciamentos passadas, na maioria dos governos, este não seria diferente com o escândalo do Bolsolão, vale refletir.

\section{REFERÊNCIAS BIBLIOGRÁFICAS}

ABBAGNANO, Nicola. Dicionário de filosofia. Tradução de Alfredo Bosi e Ivone Castilho Benedetti. São Paulo: Martins Fontes, 2007.

ANITUA, Gabriel Ignácio. Histórias dos pensamentos criminológicos. Rio de Janeiro: Editora Revan, 2008,944p.

AYALA, Marcos. Cultura popular no Brasil: perspectivas de análise. $2^{\underline{a}}$ ed. São Paulo: Editora Ática, 1995. 72p.

CONNOR, Steven. Teoria e valor cultural. São Paulo: Loyola, 1994, p.233-249 
CASCUDO, Luis da Camara. Civilização e cultura. Belo horizonte: Itatiaia limitada, 74Ip.

DURKHEIM, Émile. As Regras do Método Sociológico. São Paulo: Ed. Abril Cultural, 1983, roip

GEERTZ, Clifford. A interpretação das culturas. Rio de Janeiro: LTC S.A, 1989.322p.

HALL, Stuart. A identidade cultural na pós-modernidade. ıred. Belo Horizonte: DP\&A editora, 2003.99p.

LAPLANTINE, François. Aprender antropologia. São Paulo: Brasiliense, 1988.

LARAIA, Roque de Barros. Cultura: um conceito antropológico.24 $4^{\underline{a}}$ ed. Rio de Janeiro: Zahar, 2009.112p.

LA TAILlE, Yves de; OlIVEIRA, Marta Kohl de; PINTO, Heloysa Dantas de Souza. Piaget, Vygotsky, Wallon: teorias psicogenéticas em discussão. [S.l: s.n.], 1992.

MAUSS, Marcel. Ensaios de sociologia. São Paulo: Perspectiva, 2005. 488p

PEREIRA, Laryssa Custódio de França. Os aspectos sociais dos vários conceitos de cultura e a tese da cultura como práxis. Revista Programa de Pós-graduação de Ciências Sociais. Alagoas, v.14, n.2, p.3, Dez.2021.

TORRES, João Carlos Brum (Org.). Manual de ética: Questões de ética teórica e aplicada. Petrópolis: Vozes; Caxias do Sul: Educs; Rio de Janeiro: BNDES, 2014.

SANTOS, José Luiz dos. O que é cultura. I4 $4^{\mathrm{a} e d}$. São Paulo: Editora Brasiliense, 1994.87p.

SIMON, Sherry. Cultura in Transit. Quebec: Véhicule press, 1995, 195p

Brasil Escola

Disponívelem $<$ https://brasilescola.uol.com.br/cultura\#: : :text=O\%2osentido\%2ode\%2ocult ura\%20\% 3 3\%A9,derivado\%20das\%20artes\%2opl\% $\mathrm{C}_{3} \%$ Aisticas\%2oetc.) >Acesso em: 20 de Maio de 2021 
Bolsonaro corta $80 \%$ da verba para a cultura em 2021. Disponível em: <https://farofafa.cartacapital.com.br/2020/o8/31/bolsonaro-corta-78-da-verba-para-acultura-em-202I/.Acesso em: i4 de Maio de 202I.

AURÉliO. Dicionário do Aurélio Online 2018. Disponível em: 〈https://dicionariodoaurelio.com/cultura〉. Acesso em: 03 de Abril de 2020.

LÉVI-STRAUSS, C. Longe do Brasil. Entrevista com Véronique Mortaigne, tradução de Jorge Vilela. São Paulo: Editora UNESP, 2011, p. 29 - 30. 